\title{
Liberalismo, democracia y ordenamiento territorial
}

Rafael Carvajal Baeza*

* Profesor de la Facultad de Ciencias de la Administración de la Universidad del Valle. 



\section{INTAODUCCION}

A raíz del proceso de descentralización que se adelanta en el país desde la década de los ochenta, se ha hecho un lugar común en la reflexión de los políticos, los académicos, y aun en la opinión pública, el empleo corriente de expresiones como "comunidad participante", "participación ciudadana", "democracia participativa", etc. Este uso cotidiano parece ser una demostración de que existe a nivel institucional y ciudadano el reconocimiento de cambios importantes y trascendentales en la vida política del país, y más exactamente de una nueva forma de hacer política, más consistente que en el pasado, por decir lo menos, con el ideal democrático. Algo de eso es lo que seguramente se quiere decir cuando se sentencia el tránsito de una democracia representativa a una democracia participativa como el gran derrotero del país, apreciación cada vez más arraigada sobre todo a partir del proceso constituyente.

El objeto central de este artículo es proponer algunas precisiones conceptuales acerca de la democracia y temas afines con el ánimo de analizar con mejores elementos de juicio el alcance y profundidad de nuestras recientes transformaciones políticas. En el trayecto de esta reflexión se prescindirá del ya familiar recurso de comentar la nueva Constitución, las instituciones y procesos que reclama su efectiva aplicación. En lugar de eso (labor por demás necesaria para difundir la nueva Carta) centraremos la atención en los fundamentosideológicos del proyecto democrático (en este sentido, también se prescinde del análisis sociológico). No se trata simplemente de ver el mismo fenómeno desde otro ángulo. Como veremos, resulta un ejercicio apropiado para detectar el alcance democrático de las transformaciones presentes y la dimensión y orientación de los esfuerzos que colectivamente debemos emprender para asegurar la vigencia de este proyecto democrático.

Para una mejor y más conveniente presentación y discusión de los fundamentos ideológicos de la democracia se procederá a hacer lo correspondiente con la ideología liberal. Esto facilitará visualizar con 
mayor detalle la estructura ideológica e institucional de la democracia. Adicionalmente, discutir a la luz del debate liberalismo y democracia los recientes cambios a nivel de reordenamiento territorial.

Por último, los términos del debate aquí expuesto no pretenden cubrir la totalidad ni mucho menos, de los temas que allí se hacen cita, pero estamos seguros que al abordar la exégesis de conceptos como la libertad, la soberanía, la representación, la ciudadanía, el sufragio, etc., se contribuye al debate propuesto.

\section{VALORES E INSTITUCIONES DEL LIBERALISMO}

\section{LA LIBERTAD INDIVIDUAL}

Como es bien sabido, en la historia del pensamiento político occidental de las últimas centurias, y por supuesto en los propios avatares de su historia política, el problema del régimen de libertades y derechos ha tenido un rol protagónico debido justamente a la fuerte y directa influencia en la construcción del orden. De modo que, aunque limitados en relación al universo conceptual político de occidente, desde aquí (la libertad y otros conceptos relacionados) se proyecta una mirada al problema de la construcción del orden como esencia y preocupación permanente del quehacer político.

De entrada, lo primero que hay que decir es que este debate sobre las concepciones de la libertad ya tiene historia y puede aseverarse que ha sido una de las discusiones que mejor ha contribuido al desarrollo del pensamiento político occidental.

Una corta reseña acerca de los términos generales que han animado esta discusión nos servirá para destacar algunos de los aspectos más substanciales sobre la exégesis de la libertad de las doctrinas en cuestión.

Fue Benjamin Constant (1767-1830), el famoso publicista francés y gran teórico del liberalismo, quien en su conocido opúsculo "Discurso sobre la Libertad de los Antiguos parangonada con la Libertad de los Modernos" estableció la hermenéutica de la libertad de tipo liberal (según su expresión "de los modernos"). 
Para Constant la libertad de los antiguos, se refería a la Grecia clásica, consistía en la participación cotidiana y directa de los ciudadanos en los asuntos de Estado. Agrega que admitían como compatible con esta libertad colectiva el completo sometimiento del individuo al poder del todo. En otras palabras, nada se concedía a la autonomía del individuo como tal, como no fuera para participar en los asuntos de Estado, pero a partir de allí éste podía hacer del individuo un esclavo en sus relaciones privadas. Esto es, podía intervenir en sus asuntos privados, si cabe la expresión. ${ }^{1}$

"El ciudadano-comentó Fustel de Coulanges-se entregaba totalmente al Estado. Le daba su sangre durante la guerra, su tiempo en la paz. No era libre de dejar a un lado los asuntos públicos para cuidar de los suyos... Por el contrario, el ciudadano debería descuidarlos para trabajar por el bien de la ciudad".

El mismo autor en otro pasaje nos dice: "uno de los más extraños errores que puede cometerse es creer que en las ciudades antiguas los hombres gozaban de libertad. Cuando lo cierto es que no tenían ni la más remota idea de la misma... Tener derechos políticos, nombrar magistrados, poder ser designado arconte - a eso se llama libertad-pero no por ello los hombres eran menos esclavos del Estado".

W, Jaeger, por su parte, comenta que "la polis es la suma de todos sus ciudadanos y de todas las facetas de sus vidas. Les da mucho a todos, pero puede pedirlo todo a cambio.?

Hubo pues en la Grecia antigua un concepto de libertad que prácticamente se confundió con el culto del servicio a la polis. No extraña así que el término peyorativo idiotes -del vocablo "idiom" para referirse a lo privado- se aplicará a los no ciudadanos, quienes eran, según los griegos, hombres vulgares e ignorantes sólo interesados en sí mismos.

1 Para la discusión liberalismo y democracia véase Bobbio, Norberto en Liberalismo y Democracia: Sartori, Giovanni en "Teoría de la Democracia", Frank Cunningham Democracia y Socialismo. Problemas de Método; Losurdo, Doménico. Tradición Liberal, Libertad y Lógica de la Exclusión; Petrucciani, Stefano, Tres Conceptos de Libertad. Estostresúltimos traducidos del italiano por Alcibiades Paredes.

2. Tomado de Sartori, Guiovanni, op.cit. 
Para los modernos (los liberales de Constant) es mucho más apreciada la autonomía individual. No les interesa tanto la participación en los asuntos de Estado como la seguridad y el bienestar privado. Precisamente, las garantías para la seguridad y el bienestar privado es lo que el pensamiento liberal reconoce o denomina como libertad.

Esta libertad es la que concibe al individuo como una persona, ese yo privado que en sí mismo constituye un supremo valor amparado y tutelado por garantías derivadas de la supremacía de la ley, la defensa jurídica, y las declaraciones de derechos dirigidas expresamente a limitar las funciones y poderes del Estado -preocupación de la cual surgen las fórmulas del "Estado mínimo" y el "Estado de derecho" para asegurar las garantías y bienes del individuo-. Este es el origen de la expresión según la cual "mi derecho termina donde empieza el derecho de los demás" en la que subyace la idea de una esfera de asuntos estrictamente privados donde soólo impera el arbitrio y la autonomía individual. No faltó razón a la caracterización de la libertad liberal como proclamación de las libertades individuales. Distintas (¿y opuestas?) a las libertades políticas de la democracia antigua.

Estas pocas anotaciones del pensamiento de Constant nos bastan para relievar algunos de los puntos básicos de la hermenéutica de la libertad en la doctrina liberal. En primer lugar, el sujeto de las libertades no es el ciudadano, como en la Grecia clásica, sino el individuo y su campo de acción privada (su vida, la propiedad y sus derivaciones, etc.). En segundo lugar, y en congruencia con lo anterior, los derechos que sirven de salvaguarda a este individuo son fundamentalmente los derechos civiles (protección de la vida, la propiedad, etc.) y no tanto los derechos políticos. Es decir, aquellos que garantizan la participación en los asuntos de Estado, y que hacen del individuo un ciudadano. De otro lado, el espacio donde se ejercen estas libertades es la sociedad civil (entendida çomo el ámbito de lo privado indívidual).

Cierto es que la doctrina liberal, desde el momento en que distingue entre Estado y sociedad civil también asume el desenvolvimiento del hombre como ciudadano en el Estado e individuo en la sociedad. Pero la prioridad corresponde al individuo y sus derechos civiles. Lo que le permite concluir que "sólo la propiedad (un derecho civil natural) hace a 
los hombres capaces de los derechos políticos". ${ }^{3}$

Nos interesa ahora comentar la relación entre este concepto de libertad y el de soberanía y otros estrechamente relacionados. Muy importante para observar la proyección de los valores ideológicos en las formas de Estado (unitario, federal y regional) y el problema de la democracia.

\section{CONCEPGION LIBERAL DE LA SOBERANIAA}

Durante la Revolución Francesa la Asamblea Constituyente sostuvo la idea de que la soberanía (poder político supremo) no pertenece al pueblo o a la ciudadanía, sino a la nación representada en el Parlamento. Conviene aclarar que para los liberales la nación es un único cuerpo social en el que se disuelven los intereses y colectividades territoriales y de oficios que conoció la Edad Media, precisamente para instalar en su lugar la autonomía del individuo.

La nación deviene así en un cuerpo que reúne la masa de intereses individuales. Esos intereses no son otros que la igualdad ante la ley, la seguridad y la justicia. Se trata de principios de acción del Estado que no tienen por qué coincidir con el interés particular o circunstancial de un individuo. Por el contrario, estas funciones públicas de la nación (las propias del Estado mínimo que propuso el liberalismo) tienen el propósito de que los individuos al acatarlas respeten las libertades y derechos de los otros individuos. En otras palabras, se procedió a elaborar la idea de que la nación es un cuerpo real y distinto de cada uno de los intereses individuales, toda vez que pueden, eventualmente, violar la ley, evadir la justicia y poner en peligro la seguridad, etc.

El siguiente paso hacia la operatividad institucional del principio de la soberanía de la nación se dio al discutir el problema de su representación. En principio hubo acuerdo que el órgano indicado era el Parlamento, pero se presentó gran debate en torno a la relación del elector con el representante.

3 Tomado de Paredes, Alcibiades en "Hacia un Concepto Moderno de Democracia", publicado en Revista Sociedad", noviembre de 1988, del Departamento de Sociales de la Usaca. 
Si el titular de la soberanía es la nación y no los ciudadanos que la componen, el acto de elección que se les atribuye sólo tiene como propósito designar a los representantes de la nación. En este estricto sentido, el voto constituye una función pública. Para comprender sus implicaciones políticas, conviene exponer el punto de vista democrático.

Como se sabe, el voto en el marco de la democracia es ante todo un derecho. Y por tanto, no sólo universal sino también generador de mandatos y vínculos imperativos entre el elector y su representante. De suerte que este último está en la obligación política de gestionar en las corporaciones deliberantes (Senado y Cámara, etc.) las demandas del primero. Esa es básicamente la sustancia del concepto voto-derecho.

Pues bien, es precisamente ese carácter vinculante lo que cuestiona la doctrina liberal. La nación como ente soberano, reclama en su bien la independencia política del representante, precisamente porque el elector es portador de demandas sectoriales (de oficio, territorio, etc.). Así que, liberado de todo compromiso, el representante, se adujo, está en condición apropiada para velar por los asuntos generales de la nación (por ejemplo, la justicia) en mejor forma que los individuos, demasiado ocupados con sus bienes y propiedades.

El voto-función tiene pues, en el corpus liberal, como único propósito, designar a los representantes de la nación, ya que ella es la salvaguarda de los bienes públicos frente al interés individual.

Estas ideas las expuso con mucha lucidez el abate Sieyé en su discurso del 7 de septiembre de 1789. "El pueblo -dijo- no puede tener voluntad distinta a la de sus representantes. No puede hablar, no puede obrar, sino por ellos".

La Asamblea Constituyente fue igualmente consecuente. El artículo 3 de la Declaración de 1789 estableció: "El principio de toda soberanía reside esencialmente en la nación. Ningún cuerpo, ningún individuo puede ejercer una autoridad que no emane expresamente de ella".

\footnotetext{
4 Tomado de Bobbio, Norberto en Liberalismo y Democracia, Fondo de Cultura Económica, México 1989.

5 Ibid.
} 
El artículo 7 de la sección 3 del capítulo 1 del título 3 sentenció: "Los representantes nominados en los departamentos no serán representantes de un departamento en particular, sino de toda la nación y no se les podrá imponer a ellos mandato alguno". ${ }^{6}$

A nuestra manera los constituyentes del 86 confirmaron el espíritu liberal de la época. Decía así el artículo 179: "El sufragio se ejerce como función constitucional. El que sufraga o elige no impone obligaciones al candidato, ni confiere mandato al funcionario electo". El artículo 105 expresó lo siguiente: "Los individuos de una y otra Cámara representan a la nación entera y deberán votar consultando únicamente la justicia y el bien común". Finalmente, el artículo 106 prescribió que "los senadores y representantes son inviolables por sus opiniones y votos en el ejercicio del cargo. En el uso de la palabra sólo serán responsables ante la Cámara a que pertenecen...".

Obsérvense las ideas que subyacen. El Parlamento no representa a electores. Tampoco a la circunscripción de éstos, sino que el conjunto de los parlamentarios representa a toda la nación. De otro lado, se infiere de aquí que el voto-función niega participación en los asuntos de Estado, como quiera que prevalece la independencia del representante frente al electorado en los procesos decisorios del Estado.

Una implicación adicional importante del voto-función para el problema de la soberanía es que, al no ser un voto-derecho, su ejercicio no es universalizable, como lo entendió la democracia al reivindicar el sufragio universal. Bien por el contrario, para el credo liberal la nación, como titular de la soberanía, concede el derecho de ciudadanía como su interés le ordena sólo a aquellos que considere más dignos o más aptos. Surgieron así toda una serie de restricciones que marginaron a la gran mayoría de la población de los asuntos públicos y de Estado (lo que demuestra una vez más la prevalencia de los asuntos privados). Es el caso, por ejemplo, del voto-censitario. Es decir, sólo para grandes contribuyentes, propietarios, etc., y que resultó ser un instrumento apropiado para decapitar políticamente, por medio de las elecciones, a la aristocracia del antiguo régimen. Mass no para generar democracia, no sólo porque

$\overline{\text { lbid. }}$ 
proscribió a la mayoría de la población, también porque esta elección en tanto ejercicio de voto-función niega la participación del electorado en las decisiones de Estado y, finalmente, porque la expresión política del territorio y su comunidad (los nuevos espacios de la democracia) se diluyó en la soberanía de la nación.

A propósito de los intereses colectivos, merece prestar atención a los referentes sociológicos y políticos cuestionados por el pensamiento liberal. Sabido es que la Edad Media luego de la crisis de los proyectos políticos imperiales romano-germánicos, conoció el desarrollo de una gran variedad de organizaciones sociales; feudos, señoríos, comunas urbanas, guildas, gremios y corporaciones profesionales y de oficios de base territorial, pero que además (unas más que otras) ejercían funciones (públicas en muchos casos) dentro de un marco de autonomía para establecer su propia reglamentación como organizaciones y de las propias profesiones, oficios y territorios. Reglamentaciones que en muchos casos limitaban to que luego se conoció como libertades y derechos individuales. Esto es, libertades para ejercer una profesión, libertades para comerciar, para enajenar la capacidad de trabajo (la mercantilización de la fuerza de trabajo tan cara a Marx para explicar la acumulación originaria de capital), etc. En fin, las libertades que requería el desarrollo de la joven burguesía.?

Pues bien, la remoción de los obstáculos a las libertades del individuo se convertirá en el gran proyecto político burgués del Estado Nación en el que el soberano (en cabeza del rey en tiempos del Estado Absolutista y posteriormente en la nación en tiempos del Estado Liberal) reclamará, con éxito a la larga, atribuciones para despojar en provecho propio, a los territorios, corporaciones profesionales y demás, de su naturaleza autonómica y por extensión de su propia estructura organizativa. Se explica así la insistencia del pensamiento liberal de que el funcionario

7 Estas corporaciones podían, por ejemplo, obligar a sus miembros a vivir en un mismo sector de la ciudad, a ubicar allí mismo sus talleres. Establecían cuántos aprendices y oficiales podía tener cada miembro, qué oficiales podían ascender a maestros. Las condiciones para ello, fijaban el precio que debían pagar por sus productos, jornales, materias primas, etc.

Liberalismo, democracia y ORdenamiento territorial / Rafael CARVAJAL 
elegido no representa ni a sus electores (por lo demás muy pocos) ni a su circunscripción electoral. En otras palabras, la hegemonía del pensamiento liberal desarticuló e hizo inocua la organización de intereses colectivos, en ellos no reposó nunca la soberanía, ni siquiera la autonomía y en su lógica extrema no hubo espacio para organización alguna, aparte de la nación, y menos de tipo territorial. La sociedad liberal es masa de individuos, no de organizaciones sociales.

De esta manera, el encuentro de la ideología liberal con esa otra gran fuerza ideológica del nacionalismo abonaron el terreno para la irrupción en la escena histórica del Estado Unitario y particularmente de su modalidad centralista con su concepción estatista del poder e individualizada de la sociedad.

\section{UNITARISMO E INDIVIDUALIDAD}

Una breve caracterización del Estado Unitario es oportuna para auscultar en ella la concepción individualista que subyace y empezar así a plantear el problema de las relaciones entre democracia y formas de Estado (Estado Unitario, Estado Federal y Estado Regional).

La denominación de Estado Unitario (vigente en Colombia desde la Constitución del 86 y ratificada por la nueva Constitución en su primer artículo) es acertada porque en la organización político-administrativa de esta modalidad el poder es uno en su estructura, en su elemento humano, y en sus limites territoriales.

La organización político-administrativa es única porque consta sólo de un aparato de gobierno que lleva a cabo todas la funciones estatales, toma todas las decisiones y el ordenamiento constitucional es único. Por ejemplo, un ministerio que toma y ejecuta todas las decisiones de su competencia.

Desde el punto de vista del elemento humano, la organización político-administrativa abarca una colectividad unificada considerada globalmente (la nación) sin tomar en consideración las diferencias individuales o corporativas. Los mandatos y decisiones de la autoridad obligan a todos los nacionales de un modo igual. Por tanto, supone la extinción de todo tipo de autonomía a nivel de organización social. Más

Cuadernos de administración No 22/Universidad del Valle/Mayo de 1996 
aún, el estatismo de la fórmula hace inocua toda dinámica de organización social distinta a la nación.

Finalmente, la organización político-administrativa cubre todo el territorio de un modo idéntico, sin reconocer diferencias entre las distintas entidades territoriales. Y aún menos, expresión política propia. ${ }^{8}$

Son varios los aspectos del pensamiento liberal subyacentes en la organización unitaria. Al izar los principios de libertad e igualdad de los individuos la centralización se convierte en un medio de eliminar los privilegios y restricciones encarnados en la autonomía de que gozaban la gran variedad de cuerpos intermedios del medioevo.

De otro lado, la entronización del individuo como agente fundacional de la sociedad (según la versión del contractualismo liberal), al proscribir los intereses colectivos, en especial profesionales y territoriales, desautoriza el reconocimiento de centros de decisión corporativos y territoriales. De nuevo, la lógica del individualismo nos conduce a la fórmula unitaria.

Finalmente, la centralización y estatización de los procesos decisorios sobre asuntos públicos son un producto de la convicción de la plena realización del hombre en su privacidad e individualidad.

¿Cuál es el lugar de la figura de la descentralización en esta discusión sobre las formas de Estado? En breve, el Estado descentralizado es una clase o tipologia de Estado Unitario. Se diferencia del Estado unitario centralizado en que mientras este último implica la unidad de la estructura administrativa junto a la política para tomar y ejecutar decisiones centralizadas; el Estado descentralizado, en cambio, procede al reconocimiento de algún grado de "autonomía administrativa" en cabeza de los entes territoriales. Conserva sin embargoel espíritu unitario porque no rompe con la dirección política y administrativa de la nación (la Constitución, la ley, los dictámenes de la estructura administrativa .central, sus ministerios, departamentos administrativos, superintendencias, etc.). Pero su implementación en el contexto de una tradición centralista puede dinamizar procesos de autonomía política y democracia territorial.

Planteamientos tomado de Abadía, Juan Fernando en Estado Unitario, el Federal y el Regional, Editorial Tecnos, Madrid 1978.

Liberalismo, democracia y ordenamiento territorial / Rafael Carvajal 
Esto es lo que tiene de prometedor la reforma descentralista en Colombia.

Desde luego, no se pretende en estas pocas líneas hacer cátedra sobre el unitarismo y la descentralización. Entre otras cosas porque en estos temas el carácter fluido del escenario histórico es mucho más complejo y rico que los modelos teóricos. De tal suerte, que la descripción anterior es sólo una guía para orientar la discusión.

\section{VALORES E INSTITUCIONES DEMOCRATICAS}

\section{CONCEPCIÓN DEMOCRÁTICA DE LA LIBERTAD}

Hubo que esperar hasta fecha relativamente reciente para reformular y superar los términos del debate que sobre la libertad propuso Constant. Esa es la labor que se viene adelantando desde que los profesores Isaíah Berlin y Norberto Bobbio adoptaron la oposición "libertad negativa" versus "libertad positiva" precisamente con el objeto de analizar los avatares de la libertad en el contexto de las ideologías y no en la temporalidad histórica según la versión de Constant. Debido a ello hoy podemos discernir con más claridad las diferencias entre democracia y liberalismo (sin perjuicio de reconocer sus aspectos complementarios) a propósito de valores y de instituciones tan caros al espíritu moderno como la libertad, la soberanía, la representación, etc. Antes de entrar a observar estos aspectos conviene presentar sucintamente los rasgos generales de esta nueva discusión.

Por libertad negativa se entiende "ausencia de impedimento" para poder disponer de sí mismo "y de sus pertenencias", como diría Locke. con el mínimo de interferencia por parte de los otros individuos o del poder público. Para los defensores de esta libertad negativa, afirma Berlin, no tiene mucho interés la pregunta de "quién debe mandar" sino, "en qué ámbito soy amo y puedo obrar sin interferencia de los demás". Como resultante, la idea de libertad negativa justifica la doctrina del Estado mínimo y de los goces privados tan cara a los pensadores clásicos del liberalismo. ${ }^{9}$

V Véase Petrucciani. Stefano, op.cit. 
La libertad positiva (democrática para más señas) por el contrario, es la participación en el poder público. Idea por demás muy consistente tanto con la acepción semántica como prosaica del término según la cual, democracia es el gobierno (fenómeno por excelencia público) del pueblo. En ese sentido, la libertad para el pensamiento democrático es el "poder de no obedecer norma distinta a la que yo mismo me he impuesto" puesto que el pueblo (ese yo universalizado de Bobbio) es quien gobierna. Rousseau, por su parte, el verdadero padre de la democracia moderna, había sentenciado que la libertad democrática es "la obediencia a la ley que nosotros mismos hemos prescrito".

Por el momento es suficiente detenernos en estas pocas ideas para avanzar en la caracterización de la libertad democrática por oposición a la libertad liberal.

En primer lugar, el sujeto de la democracia es el ciudadano. Es decir, el sujeto que posee derechos políticos (por ejemplo, elegir, ser elegido, organizar partidos, etc.) pues de otra forma no podría materializarse la idea de un poder del pueblo para crear sus propias leyes y normas. O para ser menos ambiciosos, pero consistente con la hermenéutica democrática, de un pueblo que está interesado y participa en las decisiones públicas y de Estado. Esto es lo que la democracia desde la antigüedad llama libertad. Una libertad de carácter fundamentalmente política para participar en los asuntos de Estado.

Comose recordará, son precisamente estos asuntos de Estado (políticos por excelencia), los que ceden en importancia ante los asuntos privados, los que desestima el ideario liberal y por ello reivindica más el estatus de individuo (universalizable) que el de ciudadano (muy restringido). Pues bien, para la plena realización de la democracia no basta ni mucho menos el reconocimiento que haga el Estado del individuo y sus pertenencias. Seguro hay justicia en el sentido de que el poder del Estado está limitado por los derechos del individuo pero no se insistirá nunca lo suficiente en la mayor importancia que concede la idea democrática a los asuntos estatales y públicos y por tanto, la reivindicación de la ciudadanía, y las libertades y derechos políticos. 


\section{CONCEPTO DEMOCRÁTICO DE CIUDADANIA}

Siendo clara y pertinente la distinción entre los conceptos de individuo y ciudadano para efecto de apreciar su incidencia en la construcción del orden político cabe sin embargo agregar algunos comentarios sobre el problema de la ciudadanía a la luz del debate entre liberalismo y democracia. Para empezar no debe olvidarse que la figura del ciudadano no era totalmente ajena al pensamiento liberal. Tampoco a los modelos de Estado (liberales) que conoció Europa en el síglo pasado. De manera que precisamos identificar el aspecto que permita trazar una clara diferencia.

Como es bien sabido, para el liberalismo la condición de ciudadano tenía origen en el estatus civil del individuo (un gran contribuyente por ejemplo) y cuya resultante final fueron las famosas restricciones al ejercicio ciudadano proyectadas en la institución del voto censitario. En consecuencia, para la doctrina liberal, la condición de ciudadano no es universalizable. Y por ende, la sociedad es marginada de los asuntos públicos y de Estado.

Actualmente es aceptado entre los estudiosos del tema, que políticamente hablando, es decir, como praxis social, la democracia moderna es un fenómeno relativamente reciente. Habría aparecido por primera vez hacia finales del siglo pasado a raíz de las luchas por el sufragio universal, sobre todo en Inglaterra. Sin duda, esta institución no sea suficiente, pero sí una condición mínima y absolutamente necesaria para edificar la democracia como concepción de participación de la sociedad en los asuntos públicos y de Estado. En consecuencia,s la respuesta más correcta a la pregunta de quién es el sujeto de la democracia es ciertamente aquella que nos remite al pueblo, pero bajo el entendido de que esa expresión informa el hecho de que todos los miembros de la sociedad (con las excepciones que conocemos, por ejemplo de minoría de edad) gozan del derecho de ciudadanía. La democracia (moderna) es hija de la ciudadanía universal (desconocida en Grecia).

No parece desacertado interpretar que la filosofía que subyace en la institución de la ciudadanía universal y, de su correlato el sufragio universal, es que la reailización del hombre no se agota en la vida privada. 
También la vida pública (y en concreto, el Estado) es un espacio de realización de derechos. Pero esta vez de derechos políticos. Idea que se materializó en la proscripción del voto-función por el voto-derecho que expresa la prevalecencia de la demanda ciudadana sobre la voluntad del representante. El individuo reivindicaría sus derechos no sólo limitando al Estado en sus funciones y poderes (el aporte liberal), también participando en él. Es así como ha sido posible acuñar la expresión "democracia liberal" para caracterizar la evolución política, particularmente de Europa y de Estado Unidos a lo largo del siglo xx, democracia que por cierto, al reconocer y desarrollar las conquistas del liberalismo, se distingue radicalmente, de la democracia de los antiguos.

Cíudadano para la democracia no es sólo quien está facultado para elegir, como lo entendió el liberalismo. Es quien con su voto expresa un mandato al elegido. En otras palabras, quien toma en asocio con otros, decisiones de Estado.

\section{CONCEPTO DEMOCRÁtICO DE SOBERANIAA}

La conquista del sufragio universal será sólo una de las primeras reivindicaciones por los nuevos derechos políticos. Pero habrán otras de profundas y trascendentales consecuencias para el futuro político del liberalismo y la democracia. Un caso muy especial es el de los derechos de organización y de movilización política cristalizados en la irrupción de las organizaciones partidistas y sindicales por allá hacia finales del siglo pasado. Y actualmente dinamizados por la emergencia de los "nuevos movimientos sociales".

Ciertamente, el liberalismo había proclamado las libertades de pensamiento, expresión, reunión, etc., difícilmente se podría exagerar la importancia de estas instituciones para la vida partidista (una razón más para hablar hoy día de democracias liberales), sin embargo, está claro que esta relación con la democracia es sólo posible mas no necesaria. Menos aún si vemos el problema desde el ángulo estrictamente ideológico.

En efecto, para el liberalismo estas instituciones no perseguían propósitos de índole democrática. Baste aquí recordar que las restricciones al ejercicio de la ciuđadanía y el sufragio, en particular su elitización y las

Liberalismo, DEMOCraCia Y ORDENAMIENTO TERRITORIAL/ RAFAEL CARVAJAL, 
limitaciones políticas del voto-función para generar vínculos del representante con el elector, impedían que los mecanismos de elección, incluyendo algún tipo de organización del electorado alrededor de algún candidato y aun el propio Parlamento, se convirtieran en auténticos cuerpos de intermediación o canales políticos institucionalizados para informar a las altas esferas de decisión del Estado acerca de los intereses y expectativas que agitan y movilizan al electorado (recuérdese, muy reducido). En otras palabras, las limitaciones al ejercicio de la ciudadanía hacían políticamente inocuas las libertades de pensamiento, expresión y reunión. No podían, por ejemplo, cristalizar en un acto políticamente eficaz de opinión pública. La independencia del "representante" frente al electorado así lo determinó.

Con el sufragio universal y la institucionalización de los partidos políticos (hasta recientemente más de hecho que de derecho) estas libertades adquirirán auténtica naturaleza política en el sentido de instrumentos para participar en la vida pública. Pero también, y esto es quizá más relevante, en el sentido de operar una importante transformación de la vida política a través de una nueva y renovada dinámica de autonomía organizativa de la sociedad, de ingrato recuerdo para el liberalismo, en la que está en juego ni más ni menos que la topología del acto y la decisión política. Veamos.

Para el liberalismo, la política en tanto asunto público, encontró en el marco de la organización estatal su único espacio de realización, pues la sociedad civil (individuos-propietarios) ocupada en los asuntos privados poco o ningún interés tenía en los asuntos públicos. De manera que paradójicamente el Estado mínimo es, no obstante, un enteque monopoliza la actividad política. La discrecionalidad del "representante" para tomar decisiones sin consultar los intereses y expectativas del electorado es prueba palmaria de que los procesos decisorios tienen como epicentro las organizaciones de Estado.

Uno de los hechos que más suelen destacarse en la historia de los partidos políticos (en especial los partidos de masa) $)^{10}$ es la inversión en

11) Entre los caracteres más sobresalientes se destaca el trabajo de educación de las masas populares para hacerlas políticamente activas, (Continúa) 
la correlación de fuerzas entre la dirigencia partidista y su bancada parlamentaria. Se anota ahí que la lógica política de la figura o institución de la disciplina de partido tiene varias implicaciones. Todas ellas, al cuestionar las instituciones liberales sientan las bases de la concepción democrática de la soberanía.

En primer lugar, ha desaparecido la figura del representante como representante de la nación. En adelante éste es representante del partido y por extensión de su electorado. Estamos pues frente a un nuevo concepto de representación que tiene en la figura del voto programático la idea de que el elector tiene mandato y soberanía sobre el candidato elegido. Sin el cual no es posible la participación de la sociedad civil en los asuntos públicos y del Estado.

Dicho sea de paso, la democracia tiene igualmente su propio concepto de sociedad civil. Más allá del individuo propietario concibe la presencia de las expresiones libre y autónomamente organizadas de la sociedad.

En segundo lugar, congruente con el planteamiento anterior, la soberanía ya no reside en la nación y menos en el órgano que la representa (el Parlamento), la soberanía está ahora en el pueblo y sus expresiones organizadas justamente porque sus miembros poseen estatus ciudadano de modo que su voluntad canalizada en los partidos y otras organizaciones no conoce más límites que la que ella misma se impone (es aquí precisamente donde empiezan las discrepancias con el liberalismo). Por consiguiente, el concepto democrático de soberanía pone en el orden del día además del estatus ciudadano del individuo en particular, el problema de las organizaciones sociales como otras fuentes de formación de la soberanía. Se ha producido una auténtica revolución "copernicana", la soberanía que siempre reposó en el Estado (llámese la corona, la nación, etc.) reside ahora en la sociedad.

conscientes de su papel y de su fuerza, etc. Es una labor de la que luego se extraen las élites dirigentes preparadas para asumir el poder político y poner en ejecución el programa del partido. Para más información consúltese Maurice Duverger en Los Partidos Políticos. Fondo de Cultura Económica, 1980. También Guiovanni Sartori en Partidos y sistemas de Partidos, Alianza Editorial, Madrid, 1980. 
En tercer lugar, las verdaderas decisiones políticas se han adoptado en la sociedad civil a través de las agrupaciones partidistas. Aunque el parlamento sigue existiendo, la deliberación y las decisiones han sido en realidad moldeadas en el seno de los partidos. Es decir, en el seno de la misma sociedad. La política, por tanto, aparece aquí como un acto societal no patrimonio del Estado. Así pues, desde el punto de vista de lo institucional y operativo, la soberanía del pueblo para hacerse efectiva supone la proyección del sentir ciudadano (individualmente considerado) en las organizaciones sociales. Dicho de otra manera, los partidos y las organizaciones libres y autónomas de la sociedad son los órganos en los que se forma y se expresa la voluntad soberana de la sociedad. No en el "parlamento soberano" de los liberales.

En cuarto lugar, el quehacer político de la ciudadanía y sus expresiones organizadas nos advierten la presencia de un concepto fuerte de ciudadanía por oposición a uno débil expuesto por el liberalismo. Para éste, el ejercicio de la ciudadanía contempla la facultad de elegir y ser elegido. Pero esa elección no genera un mandato imperativo para el candidato elegido según lo explica la teoría de la soberanía nacional. Para la democracia, por el contrario, la elección tiene al menos una doble implicación. En primer término, se elige una autoridad (aspecto que comparte con el liberalismo y la tesis del voto-función) pero además (he aquí la diferencia), se elige un programa político (el voto-derecho). En otras palabras, mientras el ciudadano del liberalismo se limita a elegir a quienes van a tomar decisiones, el ciudadano de la democracia toma decisiones para incidir en el rumbo y la orientación de la agenda política de la dirección estatal.

\section{CONCEPCIÓN DEMOCRATICA DE LO INDIVIDUAL Y LO COLECTIVO}

Al comentar sobre el liberalismo hemos reseñado brevemente la relación entre la fórmula unitaria como principio de organización del Estado con la filosofía individualista del credo liberal.Esa relación surgió de la convicción liberal de que la libertad del individuo no precisa ningún intermediario entre éste y el Estado (basta su función de gendarme). De modo que centraliza en los cuerpos representativos de la nación (el 
Parlamento, la presidencia, etc.) la totalidad del ejercicio del poder. Por ello proscribió todo organismo colectivo (muy propios de la sociedad feudal y posteriormente de las democracias avanzadas de occidente) en especial las de tipo territorial. En otras palabras, la sociedad liberal es una masa homogénea de individuos, una sociedad que no conoce más que el conflicto entre individuos propietarios. Resoluble con la aplicación del código civil. De contera, no hay en esta sociedad espacio para los conflictos de tipo político y por tanto no precisa de la institucionalización de los derechos políticos ni de una estructura plural del Estado (federalista, regional o siquiera descentralizada) para regular e institucionalizar conflictos derivados de las distintas identidades y organizaciones políticas. Todo lo contrario, la sociedad liberal no requiere más de una misma estructura de gobierno (el famoso gendarme) celosa en la aplicación de un único código civil para todo el territorio y sus habitantes.

La presencia y evolución de los partidos políticos vino sin embargo a controvertir las tesis liberales sobre la centralidad y prevalencia del interés individual y desde luego, del espíritu tendencialmente unitario del Estado liberal.

Para empezar, la polarización política y partidista de la sociedad a raíz del desarrollo de los grandes ejes de tensión de las sociedades modernas vino a rescatar el principio de Ja autonomía organizativa para defender un sin número de intereses y valores en juego desde el momento en que empezaron a ser percibidos como líneas de ruptura de la sociedad; la lucha entre credos y confesiones religiosas (la Reforma y Contrarreforma Protestante) poco después, el conflicto de potestades entre Estado e Iglesia, más adelante entre clases (obreros, campesinos, patronos, etc.) avanzando aún más, entre intereses urbanos versus agrarios y así sucesivamente hasta llegar hoy en día nuevamente al conflicto entre lo territorial (de tipo local, municipal, provincial, departamental, estadual, regional, etc.) frente a lo nacional y aún lo internacional. En todos estos eventos la organización y movilización colectiva libre y autónoma frente al Estado planteó el problema de la estructura y orientación de las gestiones de Estado.

Se ha señalado, por ejemplo, que la institucionalización de los partidos vino a clausurar la concepción liberal del parlamentarismo. En 
segundo término, puso en la agenda del día las legislaciones e instituciones especializadas desde el punto de vista social (legislación laboral, agraria, etc.) que de hecho cuestionó la unidimensionalidad del individuo como propietario para hacerlo miembro y participe de una comunidad de intereses con vida e intereses propios (la acción sindical, ligas campesinas, partidos de clase, partidos de ideas, la politización de los roles sociales y grupos de referencia "naturales" expresada en asociaciones de padres de familia, organizaciones étnicas, de vecindad, como usuarios, etc.). Por último, la creciente territorialización de éstas y otras organizaciones ciudadanas configuran a las divisiones administrativas del Estado unitario (departamentos y municipios) comoespacios de acción política autónoma precisamente con el objeto de asegurar la participación en los asuntos públicos de las organizaciones de base territorial. Sin embargo, esto no serápolíticamente eficaz, como veremos luego, hasta tanto no se desmonte la estructura unitaria del Estado.

Nunca se insistirá lo suficiente en el principio de la organización libre y autónoma." Para preservar a la sociedad un campo de acción que disputa al Estado liberal el monopolio de la política. En primer lugar, porque en el marco de la autonomía las organizaciones sociales se dan su propio reglamento, y en segundo lugar, elaboran y gestionan demandas y propuestas colectivas de interés público. Gestión que para ser políticamente eficaz supone que es reconocida por el Estado. Supone que las organizaciones sociales son sus interlocutores válidos. Por tanto, cuando los individuos se asocian es para hacer política. Se convierten ahora si, en un "zoon politikon". Este individuo defiende sus fueros ya no sólo limitando al Estado, como lo entendió el liberalismo. También se defiende participando en el Estado.

Sin embargo, a diferencia de la democracia antigua cuando la participación del ciudadano se hacía en forma directa. Es decir, sin cuerpos intermedios. La democracia moderna, por el contrario, requiere

11 En efecto, la historia registra la existencia de organizaciones, incluso poderosas organizaciones "sociales" carentes de los atributos de libertad y autonomía. Este es el caso de las organizaciones-apéndice de los Estados Totalitarios en los que el primado de la ideología del partido único priva a la sociedad del derecho a organizarse con libertad y autonomía. 
de éstos. Este fenómeno es el que se ha dado en denominar democracia pluralista. En la que la expresión pluralismo hace referencia a la multiplicidad de organizaciones sociales (ante todo una situación objetiva) con variada visión del mundo y de los problemas del diario vivir, de forma que en su conjunto dan vida a una opinión pública heterogénea que aspira a través del desarrollo de los derechos políticos (el encuadramiento ideológico de la militancia, de sus simpatizantes, el acceso a la información oficial, el derecho de réplica, el acceso a los medios de comunicación, etc.) influir en la toma de decisiones del Estado y la sociedad.

Esto hace del principio de la libre organización (para hacer política) elemento sustancial del interés público. No basta por tanto, asegurar la aplícación de los derechos y el código civil. La democracia entiende la necesidad de avanzar en el campo de los derechos políticos.

No debe pasar inadvertido que en el principio de la libre organización hay un sano y provechoso encuentro entre liberalismo y democracia en situación, es verdad, de equilibrio inestable pero al fin equilibrio. Sin embargo, conviene dejar muy en claro que es un "encuentro", no una fusión o un desarrollo necesario e inevitable de lo uno (el individuo) hacia ló otro (la libre organización). Son muchos los testimonios históricos del desencuentro y de las luchas para que el Estado reconozca la calidad de interlocutor válido (con todo lo que ello implica para desplazar y multiplicar los centros de decisión política) de las organizacioneśs sociales. En una palabra, para que se democratice. Esto es lo que precisamente está en juego con las políticas y estrategias de reordenamiento territorial.

\section{DEMOCRACIA, PLURALISMO Y REORDENAMIENTO TERRITORIAL}

Para los analistas del futuro de la democracia ${ }^{12}$ la materia prima de su desarrollo está antes que todo en un hecho social objetivo, que cada quien trata de interpretar. Se trata de la renovada recreación del tejido social a partir de nuevos problemas e ideales (ecologismo, politización de distintos roles sociales como la calidad de usuario, vecino, etc.). Pero esta vez, a

12 Consultar Bobbio, Norberto en El Futuro de la Democracia, Plaza y Janés. 1985. 
diferencia de las experiencias anteriores, como los partidos de masa y el sindicalismo, su base organizativa tiene asiento en el territorio y otros espacios sociales cercanos al individuo (la escuela, el vecindario, el centro de salud, etc.).

Para el discurso democráticoéstos son los nuevos campos de ampliación y profundización de la democracia. Básicamente el planteamiento es que la democracia y a no crece respondiendo a la pregunta del quién vota, toda vez que el sufragio universal, aún con sus restricciones, lleva la democracia a un punto muy cercano a su límite. Por tanto, la pregunta es dónde vota el ciudadano o, para ser más preciso, dónde toma decisiones públicas. Se ha creído que la respuesta a esta pregunta es la que realmente orienta la discusión sobre el desarrollo de la democracia. Pero al indagar por los ajustes institucionales que fomenten y activen estas nuevas organizaciones en su propósito de ser reconocidas como interlocutores válidos del Estado, se encuentra la necesidad de descentralizar la organización del Estado con el fin de crear canales de diálogo y concertación más adecuados y cercanos a la comunidad libremente organizada.

Este ajuste institucional pasa desde luego, por el reordenamiento territorial. Es decir, por estrategias que conduzcan al reconocimiento de los derechos políticos del territorio (local, municipal, departamental, estadual, provincial, regional, etc.) para gestionar por sí mismos la agenda de sus propios asuntos. Por ello es de la mayor importancia avanzar en la discusión sobre la desconcentración, la descentralización y la autonomía territorial, pues de otra manera, la iniciativa política de la comunidad territorial tropezará con las directrices del centralismo ejercido por la nación.

En franca oposición al espíritu del Estado unitario, las políticas de reordenamiento territorial en el contexto de países de larga tradición unitaria como el nuestro, deben orientarse de tal modo que al reconocer el carácter plural y organizativo de la sociedad se avance hacia la apertura política a la autonomía de las expresiones organizadas de la sociedad y la configuración de estructuras de decisión y ejecución políticamente diversas.

El órgano más adecuado y a la mano para ello son precisamente los territorios, que vienen así a constituirse eventualmente (no necesariamente) 
en los nuevos espacios de ampliación y profundización de la democracia.

Resulta forzoso así concluir que la fórmula del Estado unitario no es compatible con los avances de la democracia. ${ }^{13} \mathrm{La}$ proscripción del territorio a mera división administrativa cancela toda posibilidad de democracia a nivel territorial. Desde este punto de vista, el unitarismo es una institución anacrónica.

Esta es la razón que explica la importancia de abordar el estudio de la democracia en relación con las formas de Estado, y por su puesto, el motivo de la gran expectativa frente al proceso de descentralización que adelanta el país. Pues a pesar de que no constituye una ruptura con la tradición unitaria, puede eventualmente dinamizar la apertura de procesos democráticos.

Precisamente en el interés de avanzar en la discusión de la democracia se inspira el tono crítico de las observaciones subsiguientes.

\section{DEMOCRACIA Y DESCENTRALIZACION EN COLOMBIA}

A lo largo de estas líneas hemos querido aclarar qué es y qué no es democracia y liberalismo. Para ello hemos presentado y discutido brevemente sus valores, conceptos e instituciones. En ese recorrido se ha encontrado que aunque se comparte el uso de expresiones y categorías de amplio recibo y aceptación en los ámbitos políticos, académicos y de opinión pública, tales como libertad, soberanía, representación, elección, voto, ciudadanía, etc., hay sin embargo una clara y nítida diferenciación en los contenidos y alcances políticos (véase Cuadro Resumen). Esto nos debe permitir examinar con apropiados elementos de juicio el Estado del arte en la construcción de la democracia en Colombia. En esta oportunidad nos limitaremos a llamar la atención sobre posibles equívocos y desinformadas apreciaciones sobre el proceso de reordenamiento territorial que adelantamos en Colombia y el discurso democrático.

13 Subrayo avances para dejar claro que no necesariamente unitarismo y democracia configuran una relación imposible. 
Una de las reformas más importantes para avanzar en este proceso fue la elección popular de alcaldes y posteriormente de los gobernadores. En principio no hay duda que frente a la larga tradición centralista y presidencialista del país, las alcaldías y gobernaciones populares son un paso importante para avanzar en la creación de nuevas estructuras de decisión política legitimadas por el voto ciudadano. Baste considerar que ésta es una de las piezas centrales de una auténtica reforma territorial precisamente para poner fin a la prevalencia de la estructura políticoadministrativa de la nación. De modo que la elección popular de mandatarios territoriales con período fijo son una sana y conveniente forma de asegurar un mínimo de autonomía del territorio, sus autoridades y su comunidad frente a la autoridad nacional (Presidencia, Congreso, etc.).

Sin embargo, no es ocioso recordar que la elección por sí sola no genera democracia. Para ello es necesario, absolutamente necesario, que a través de la elección las expresiones organizadas de la comunidad territorial participen en las deliberaciones y decisiones de Estado (adviértase que la elección de un mandatario es una decisión de la sociedad, no del Estado). En consecuencia, lo que nos interesa saber para determinar la presencia de instituciones democráticas en el nivel territorial no es la elección de sus gobernantes sino en qué medida a través de los comicios las organizaciones de base inciden en la orientación de las gestiones de Estado, Sin este elemento a lo mejor tenemos un territorio políticamente autónomo frente a la nación pero no necesariamente democrático.

Otro aspecto bien problemático en la promesa del nuevo territorio es el conocido fenómeno de la apatía ciudadana expresada en la escasa concurrencia a las elecciones y, más en general, en el poco interés por los asuntos públicos y de Estado, y que según parece también se presenta en las nuevas entidades territoriales. Esta apatía constituye de veras una preocupante amenaza al proyecto democrático pues nos informa el repliegue de los asociados al recinto de su privacidad, negación absoluta de la democracia. Tendríamos así a lo más individuos prósperos, pero ciudadanos de pobre categoría para realizarse en el bien público y la solidaridad. 
De nuevo pues, no basta registrar periódicamente la celebración de elecciones (incluso en ámbitos sociales como la escuela, la empresa, la vecindad, etc.) si la escasa concurrencia confirma y reproduce estructuras de dominio patrimonial. Justamente, el gran derrotero de la ciudadanía y el sufragio universal es la socialización del Estado (no la estatización de la sociedad como aconteció en el socialismo real). Su conversión en un campo para la institucionalización y resolución pacífica de todo conflicto social.

Uno de los fenómenos que más ha suscitado el interés de diversos públicos es la creciente proliferación de organizaciones políticas, asociaciones y movimientos cívicos por fuera del espectro bipartidista. Es una buena noticia para la democracia, pero antes de anunciarla, ganamos bastante si nos detenemos a observar su problemática. En primer lugar, el riesgo cierto de la cooptación de estas organizaciones por los partidos tradicionales y la propia izquierda, amenazan su identidad y autonomía política. En segundo lugar, la reproducción de estructuras centralistas, caudillistas y piramidales que frustran las expectativas de militantes y simpatizantes de base. En tercer lugar, los problemas que obstaculizan el diálogo, la interlocución y la concertación con el Estado. Problemas que por cierto pueden tener origen en el propio Estado (la inercia de las rutinas de gestión tradicionales y autoritarias) pero también en la propia organización por carecer de capacidad propositiva para políticas serias y viables. Cualquiera sea la circunstancia, éstos son problemas que al entorpecer la interlocución con el Estado hacen inocua la dinámica organizativa para convertirse en sólidos soportes de la participación política y tienden a convertirse, o peor, a reducirse en desesperados mecanismos de sobrevivencia.

Es cada vez más amplio el consenso en torno a las políticas de privatización y racionalización de las empresas de Estado como piezas adicionales de las políticas de descentralización. Eincluso, según algunos, son una forma de descentralizar. Esto incluye a las empresas de orden municipal y territorial en general. Quienes las promueven suelen insistir en los beneficios políticos (transparencia), sociales (mejor servicio) y económicos (racionalidad económica) tanto para las instituciones y la comunidad territorial. Seguramente no les falta alguna razón. Pero aún en

Liberalismo, democracia Y ORdENAMIENTo territorial / RaFAel CARVAJAi. 
caso del mayor éxito, no podrían las políticas de privatización, modernización de la gestión y de aplicación de los principios del mercado y el individualismo a los asuntos públicos, impulsar el avance de la democracia, toda vez que subsiste el problema de cómo participa la comunidad libremente organizada en el "remanente" estatal "mínimo" que propone el liberalismo desde sus orígenes ${ }^{14}$ Podríamos eventuaimente, en ausencia de esa participación, incrementar el bienestar, incluso el bienestar colectivo, mejorar la prestación de servicios públicos pero no olvidemos que la apuesta de la democracia liberal es el bienestar con libertad política. Por ello reconoció en el "socialismo real" su gran enemigo histórico a pesar de los avances innegables en el desarrollo social.

Finalmente, no se insistirá nunca lo suficiente en el profundo sentido de la participación en los asuntos de Estado. Para ser más concretos, en las decisiones de Estado. Tener claro esto es fundamental para apreciar la diferenciay la distancia con la elección de "representantes" y gobernantes que concibió el liberalismo. Y que redujo el acto ciudadano a elegir los miembros de los órganos de decisión. Que de ahí en adelante están autorizados para actuar con independencia respecto del elector. Por ello se acuñó con justicia y acierto la figura del Parlamento soberano y el votofunción.

Para la democracia el principio de la soberanía popular convierte el voto en un mandato del elector y es por tanto un voto-derecho. Pues bien, este mandato del electorado precisa, como hemos visto, no sólo de organizaciones civiles libres, autónomas y gran poder de convocatoria ciudadana. Precisa además que la estructura de reordenamiento territorial reconozca autonomía para que las autoridades territoriales canalicen e institucionalicen las demandas ciudadanas. Sobre temas tan diversos como asignación de prioridades en materia de inversiones sociales, adecuación de las estructuras y procesos de decisión a la cultura política territorial. autonomía fiscal, autonomía para la gestión de vínculos y

is Por otra parte repárese que la privatización de los servicios públicos no modifica la naturaleza pública de los mismos. Son por tanto preocupación de la democracia. 
relaciones económicas, políticas e interterritoriales (incluso extranjeras) etc. De otra manera, las nuevas autoridades pueden ver reducido su papel al de ejecutores con cierto margen de autonomía, hay que reconocerlo, de políticas centrales, mas no de expectativas y demandas de la comunidad territorial como lo reclama el espíritu de la democracia. Sin autonomía territorial no hay democracia territorial.

Vale la pena entonces indagar qué tanto avanzamos los colombianos hacia la democracia con la Ley 60 de 1993 sobre distribución de recursos y competencias territoriales, con sus innumerables y cada vez más discutidas rigideces fiscales, políticas y administrativas. $Y$ de contera, la escasa autonomía de la autoridad y la comunidad territorial.

¿Qué es en realidad lo que se persigue con este instrumento y las políticas de descentralización en general?

¿Avanzar hacia el desarrollo social? O si quiere, ¿en la democracia social?

¿Mejorar la eficacia y la eficiencia del Estado en la prestación de los servicios públicos?

¿Está en el espíritu de esta ley y del proceso en general, hacer compatible el discurso de la eficiencia con el discurso de la democracia?

De ser compatibles ¿qué importancia u orden de prioridad tienen la eficiencia y la democracia en las políticas que se adelantan?

No es el ánimo del llamado a este análisis polemizar sobre ésta y otras leyes de incidencia territorial, pues no es ésta la oportunidad. Se trata más bien, de reparar en la orientación y magnitud de los esfuerzos para poner en marcha un auténtico proyecto democrático; sacudir el individualismo, ampliar y diversificar la dinámica organizativa de la sociedad, incorporar la presencia de la comunidad organizada en los procesos de decisión y aún en las rutinas de la gestión pública, profundizar el proceso de descentralización y, por qué no, permitirnos dudar del estatuto unitario que aún preside nuestro ordenamiento territorial. 
CUADRO RESUMEN

\begin{tabular}{|c|c|c|}
\hline VALORES E INSTITUCIONES & LIBERALISMO & DEMOCRACIA \\
\hline CONCEPTO DE LIBERTAD & Libertad individual & Libertad política \\
\hline EsPaCIO dE EJERCICIO & Vida privada & Vida pública \\
\hline SUJETO dE LiberTAD & Individuo & Ciudadano \\
\hline $\begin{array}{l}\text { GARANTIA } \\
\text { JURIDICO-POLITICA }\end{array}$ & $\begin{array}{l}\text { Derechos civiles } \\
\text { (Código Civil) }\end{array}$ & Derechos políticos \\
\hline CONCEPTO DE SOBERANIA & Nación (Estado) & Pueblo (Sociedad) \\
\hline $\begin{array}{l}\text { ORGANO DE FORMACIÓN Y } \\
\text { EXPRESIÓN DE LA VOLUN- } \\
\text { TAD SOBERANA }\end{array}$ & Parlamento soberano & $\begin{array}{l}\text { Organizaciones sociales } \\
\text { libres y autónomas }\end{array}$ \\
\hline CONCEPTO dE CIUDADANO & $\begin{array}{l}\text { Facultad de elegir } \\
\text { miembros de cuerpos } \\
\text { decisorios }\end{array}$ & $\begin{array}{l}\text { Facultad de expresar } \\
\text { mandatos y decisiones } \\
\text { de Estado }\end{array}$ \\
\hline $\begin{array}{l}\text { CONCEPTO DE } \\
\text { REPRESENTACIÓN }\end{array}$ & De la Nación & Del pueblo \\
\hline CONCEPTO DE VOTO & $\begin{array}{l}\text { Voto-función. } \\
\text { voto-censitario }\end{array}$ & $\begin{array}{l}\text { Voto-derecho, sufragio } \\
\text { universal }\end{array}$ \\
\hline CONCEPTO SOCIEDAD CIVIL & $\begin{array}{l}\text { Individuos-propietarios- } \\
\text { mercado }\end{array}$ & $\begin{array}{l}\text { Organizaciones } \\
\text { sociales libres y autónomas }\end{array}$ \\
\hline
\end{tabular}

Cuadernos de administración Nº 22/Universidad del Valle/Mayo de 1996 


\section{BIBLIOGRAFIA}

Abadfa, Juan Fernando. Estado Unitario, el Federal y el Regional, Editorial Tecnos, Madrid 1978.

Bobbio, Norberto. El Futuro de la Democracia, Plaza y Janés, 1985.

Liberalismo y Democracia, Fondo de Cultura Económica, México 1989.

Duverger, Maurice. Los Partidos Políticos, Fondo de Cultura Económica, 1980.

Instituciones Políticas y Derecho Constitucional, Editorial Ariel, 1984.

Frank Cunningham. "Democracia y Socialismo. Problemas de Método", Mimeo traducido del italiano por Paredes, Alcibiades, publicado en "Crítica Marxista". No.6, 1989.

Held, David. Modelos de Democracia, Alianza Universidad, 1992.

Losurdo, Doménico. "Tradición Liberal, Libertad y Lógica de la Exclusión". Mimeo traducido del italiano por Paredes, Alcibiades, publicado en Marxe il Bilancio Storico del Novecento.

Paredes, Alcibiades. "Hacia un Concepto Moderno de Democracia", Revista Sociedad, noviembre de 1988, Departamento de Sociales, Usaca.

Petrucciani Stefano. "Tres Conceptos de Libertad". Mimeo traducido del italiano por Paredes, Alcibiades, publicado en "Crítica Marxista". Analisi e Contributi per Ripensare la Sinistra. No.1, 1992, Roma.

Sartori, Giovanni. Teoría de la Democracia, Fondo de Cultura Económica, México 1989. 